\title{
Application GIS technology to determine the land price in Ward 10, District 8, Ho Chi Minh City
}

\author{
Duc Huu Hoang ${ }^{1}$, Lan Thi Pham 2, , Ha Thu Thi Le ${ }^{2}$, Phi Hoang Nguyen², Hai Quoc \\ Duong ${ }^{2}$, Huynh Hoang Luu ${ }^{2}$, Cuong Duy Khuat ${ }^{3}$, Hieu Thanh Nguyen ${ }^{4}$ \\ ${ }^{1}$ Ho Chi Minh University of Natural Resources and Environment, Ho Chi Minh City, Vietnam \\ ${ }^{2}$ Hanoi University of Mining and Geology, Hanoi, Vietnam \\ 3 Technical centrer for natural resources, environment and land development Lam Dong, Lam Dong, \\ Vietnam \\ ${ }^{4}$ Khanh Hoa Environment and Natural Resource Department, Khanh Hoa,Vietnam
}

ARTICLE INFO ABSTRACT

Article history:

Received 05 ${ }^{\text {th }}$ Apr. 2021

Revised 08 $8^{\text {th }}$ July 2021

Accepted $31^{\text {st }}$ July 2021

\section{Keywords:}

GIS,

Ho Chi Minh city,

Land price.
Determination of land price is one of the most important land management roles. Land prices and changes of land prices are evident in the real estate market. The real estate market plays an important role in the economy of Vietnam. Recently, when the population is increasing, leading to increased housing demand. The distribution of the population is concentrated in big cities. Then the demand for land information, especially land prices are always interested by people. However, real information on land price is always lacking and virtual. If people want the real estate market to develop well, information on land price must be clear and adequate. The land price area map satisfies those requirements. Land price zone map helps managers about land effectively and the land price map also helps the people - participants in the real estate market to grasp the most reliable information of land prices. GIS technology is applied in the paper to zone land prices using land price information collecting in Ward 10, District 8, Ho Chi Minh City

Copyright (C) 2021 Hanoi University of Mining and Geology. All rights reserved.

${ }^{*}$ Corresponding author

E - mail: phamthilan@humg.edu.vn

DOI: 10.46326/JMES.2021.62(4).06 


\title{
Tạp chí Khoa học Kỹ thuật Mỏ - Địa chất
}

\section{Ứng dụng công nghệ GIS xác định giá đất khu vực Phường 10, Quận 8, TP. Hồ Chí Minh}

\author{
Hoàng Hữu Đức ${ }^{1}$, Phạm Thị Làn 2,, Lê Thị Thu Hà 2, Nguyễn Hoàng Phi 2, Dương \\ Quốc Hải ${ }^{2}$, Lưu Hoàng Huynh ${ }^{2}$, Khuất Duy Cường ${ }^{3}$, Nguyễn Thành Hiếu ${ }^{4}$ \\ ${ }^{1}$ Trường Đại học Tài nguyên và Môi trường, TP. Hồ Chí Minh , Việt Nam \\ 2 Truờng Đại học Mỏ Địa chất, Hà Nội, Việt Nam \\ 3 Trung tâm kỹ thuật tài nguyên môi trường và phát triển quỹ đất tỉnh Lâm Đồng, Lâm Đồng, Việt Nam \\ ${ }^{4}$ Sở Tài nguyên và Môi trường Khánh Hòa, Khánh Hòa, Việt Nam
}

\section{THÔNG TIN BÀI BÁO TÓM TẮT}

\section{Quá trình:}

Nhận bài 05/4/2021

Sưa xong 08/7/2021

Chap nhận đăng 31/7/2021

Tùr khóa:

Giá đất,

GIS,

TP Hồ Chí Minh.
Xác định giá đất là một trong những nhiệm vụ quan trọng của công tác quản lý đất đai. Giá đất thực tế và nhũng biến động về giá đất thể hiện rõ trong thị trường bất động sản. Thị trường bất động sản (BĐS) có vai trò quan trọng trong nền kinh tế của nước ta. Đặc biệt trong nhũng năm gần đây, khi dân số ngày một tăng, kéo theo nhu cầu nhà ở tăng và tập trung ở các thành phố lớn, làm cho nhu cầu thông tin về đất đai, đặc biệt là giá đất luôn được người dân quan tâm. Trong khi đó, thông tin về BĐS luôn thiếu và chưa đáng tin cậy. Để thị trường BĐS phát triển tốt thì yêu cầu thông tin phải rõ ràng, đầy đủ và minh bạch. Bản đồ vùng giá đất giúp các nhà nước quản lý đất đai một cách hiệu quả, đáp úng được yêu cầu đó. Đồng thò̀i bản đồ vùng giá đất còn giúp nhũng người dân - người tham gia thị trường $B Đ S$ nắm được nhũ̃ng thông tin đáng tin cậy nhất về giá đất. Bài báo sử dưng công nghệ GIS để xác định giá đất theo thông tin giá thị trường đã thu thập được tại Phường 10, Quận 8, Thành phố Hồ Chí Minh.

(C) 2021 Trường Đại học Mỏ - Địa chất. Tất cả các quyền được bảo đảm.

\section{Mở đầu}

Nằm trong xu thế chung của đất nước, Thành phố Hồ Chí Minh (TP.HCM) có sự đô thị hóa mạnh mẽ do sự gia tăng dân số đã dẫn tới sự biến động

*Tác giả liên hệ

E - mail: phamthilan@humg.edu.vn DOI: 10.46326/JMES.2021.62(4).06 lớn về giá đất, đặc biệt là Quận 8, TP.HCM là nơi diễn ra các hoạt động buôn bán bất động sản rất sôi động. Sự nhộn nhịp của thị trường BĐS đã làm cho giá đất của Quận 8 thay đổi liên tục và giá đất dễ dàng bị thổi phồng từ các nguồn tin chưa đáng tin cậy. Bên cạnh đó, việc đầu cơ đất cũng là động lực làm lên giá trị đất từ việc thay đổi mục đích sử dụng đất (Hermawan \& Syahbana, 2015). Để thực hiện tốt công tác quản lý đất đai và để đảm bảo người dân có thể mua bán giá đất thực nhất thì 
việc xác định giá đất khu vực Quận 8 cần thiết. TP.HCM cũng có những quyết định về giá đất như quyết định số 02/2020/QĐ - UBND của TP.HCM ngày 16 tháng 01 năm 2020 về ban hành Quy định về Bảng giá đất trên địa bàn TP.HCM giai đoạn 2020 - 2024. Quy định này phân chia vùng giá đất theo mục đích sử dụng và tiêu chí định giá chủ yếu dựa vào vị trí của thửa đất so với đường giao thông như quốc lộ, tỉnh lộ, các con phố và các hẻm. Bên cạnh đó, quy định về giá đất TP.HCM nói chung và Quận 8 nói riêng cũng chỉ đang dừng ở việc mô tả giá đất tại các vị trí theo các bảng phụ lục và báo cáo mô tả theo khung của chính phủ quy định. Hiện tại, bản đồ về giá đất theo thị trường vẫn chưa có và sự biến động về giá các thửa đất trên thị trường không được cập nhật thường xuyên. Trong khi đó, mỗi thửa đất nằm ở một vị trí không gian nhất định, giá trị thực của mỗi thửa đất ngoài việc phụ thuộc vào vị trí so với đường giao thông (Paul B. Downing, 1973; Aransah Sembiring và nnk., 2019), còn phụ thuộc vào vị trí so với trường học (Aliyu Ahmad Aliyu và nnk, 2016), cơ sở y tế (Ryan Rivas và nnk, 2019; Waddell $\mathrm{P}$ và nnk, 1993), chợ, siêu thị, khu vui chơi giải trí (Turner J, 2017), tính pháp lý (Oni Ayotunde Olawande và nnk, 2012), tiếng ồn và ô nhiễm môi trường (Van Praag $\mathrm{B}$ and Baarsma $\mathrm{BE}, 2001$; Ozdenerol $E$ và nnk, 2015),... thêm vào nữa giá của các thửa đất đó còn biến động rất nhanh theo thời gian. Để nâng cao hiệu quả quản lý nhà nước về đất đai, giúp tăng cường hiệu lực cải cách thủ tục hành chính trong lĩnh vực đất đai và đặc biệt đối với các công việc có liên quan đến các hoạt động đầu tư kinh doanh và để có sự minh bạch thông tin giá đất trên thị trường bất động sản thì cần thiết phải có cơ sở dữ liệu về hệ thống định giá đất để sát với thực tế nhất. Như vậy, phân vùng giá đất là một nhu cầu thực tiễn của nền kinh tế thị trường (Trịnh Hữu Liên, 2014), để đáp ứng nhu cầu của thị trường cũng như đáp ứng nhu cầu của công tác quản lý đất đai. Để giải quyết được nhu cầu thực tế này, cần thiết phải xây dựng bản đồ giá đất với sự trợ giúp của công nghệ GIS.

Công nghệ GIS với khả năng lưu trữ, chuẩn hóa, trình diễn số liệu trực quan trên bản đồ, phân tích và cập nhật dữ liệu sẽ là công cụ hiệu quả để xây dựng hệ thống cơ sở dữ liệu GIS nhằm tích hợp các yếu tố ảnh hưởng đến việc xác định giá đất khách quan, chính xác và kịp thời nhất cho Quận 8, TP.HCM.

\section{Khu vực nghiên cứu dũ̃ liệu}

Phường 10 thuộc Quận 8, TP.HCM, có diện tích 25,48 ha, dân số năm 2006 là 22.267 người, mật độ dân số đạt 87,748 người $/ \mathrm{km}^{2}$. Phường 10 có vị trí địa lý nằm ở nằm phía bắc trung tâm Quận 8 , giáp ranh với các đơn vị hành chính. Phía bắc giáp với Phường 11, ranh giới là Rạch Ụ Cây; phía đông giáp với Phường 9 , ranh giới đường Hưng Phú và cầu Nguyễn Tri Phương đến cầu Chánh Hưng; Phía tây giáp với Phường 11; phía nam giáp với Phường 5 , lấy ranh giới là kênh Đôi (Hình 1).

Với vị trí thuận lợi, Phường 10 có tiềm năng để thu hút vốn đầu tư trong nước và nước ngoài cho phát triển như ngành công nghiệp và xây dựng phát triển đô thị.

Cùng với sự phát triển của hệ thống hạ tầng là các dự án cải thiện môi trường nước, các dự án bồi thường hỗ trợ, tái định cư nhà ở ven sông, các dự án công viên cây xanh dọc kênh, rạch,... Đến nay, Phường 10 dần thoát khỏi tình trạng "vùng nước

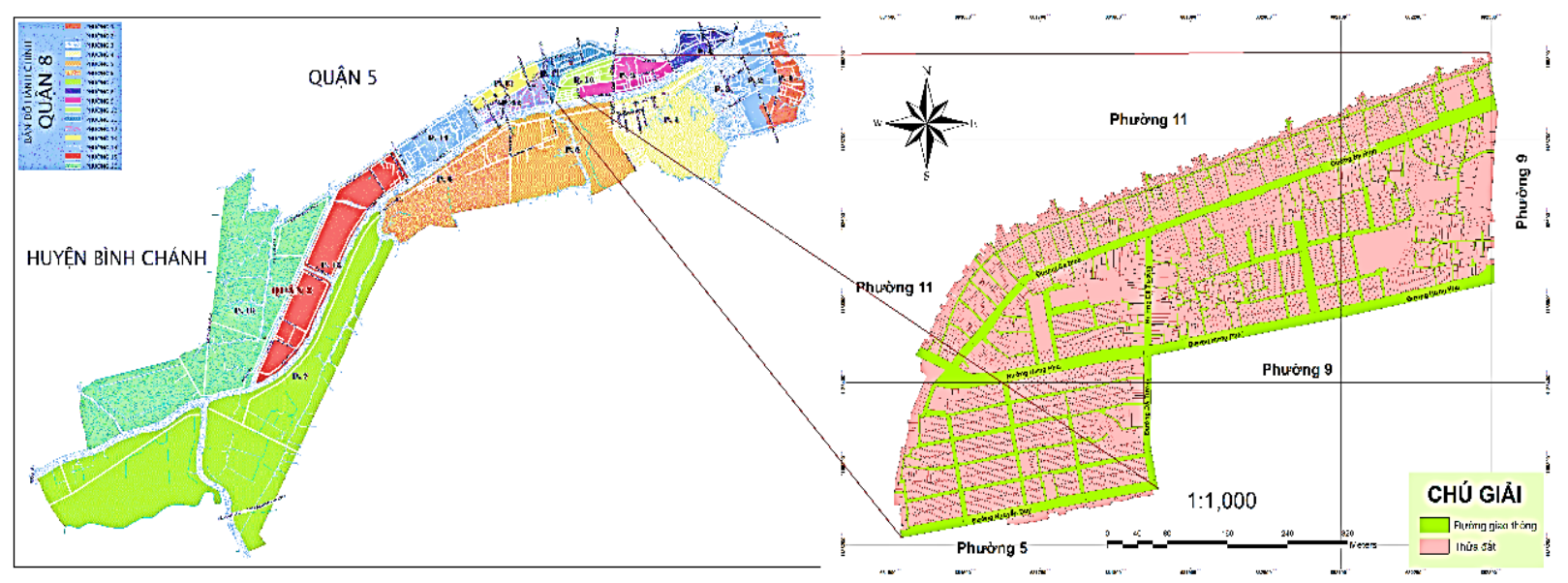

Hình 1. Vị trí địa lý Phường 10, Quận 8, TP. Hồ Chí Minh. 
đen” của khu vực. Dữ liệu sử dụng trong bài báo gồm bản đồ địa chính, bản đồ giá đất theo giá nhà nước và số liệu điều tra giá đất trên thị trường của Phường 10, Quận 8, TP.HCM.

\section{Phương pháp nghiên cứu}

Giá đất được tính theo giá thị trường kết hợp với yếu tố ảnh hưởng là vị trí, diện tích và hình dạng thửa đất. Giá đất thị trường trong bài báo được tính toán công thức (1) và quy trình thực hiện theo Hình 2.

$$
\begin{aligned}
& \text { Giá quy chuẩn = Giá đất (điều tra trên thị } \\
& \text { truờng }) /(\text { K_vitri*K_dientich*K_hinhthe) }
\end{aligned}
$$

\section{Kết quả và thảo luận}

\section{1. Điều tra, thu thập số liệu}

Để xác định giá đất theo khung giá thị trường thì trước tiên cần phải đi thu thập số liệu giá thị trường. Việc thu thập phải dựa trên nguyên tắc là phân bố đều các mẫu trên khu vực nghiên cứu, giá đất thu thập được phải được loại bỏ sơ bộ những giá quá xa thời điểm nghiên cứu hoặc vô lý (cao quá mức hoặc thấp quá mức) để đảm bảo giá thu thập được mới và sát với thực tế nhất có thể.

Các thông tin về giá đất có thể tìm kiếm được từ chủ thể sử dụng đất đã giao dịch, các cơ quan chức năng, báo chí, mạng internet, văn phòng nhà đất, sàn giao dịch,... Các thửa đất đã được điều tra cần được phải đánh dấu trên bản đồ địa chính để phục vụ cho việc nhập giá và tiến hành nội suy. Các số liệu thị trường thu thập được có thể chỉ có giá đất hoặc bao gồm cả giá đất và giá nhà (gọi là giá bất động sản). Vì vậy, cần phải tách riêng hai loại (Giá đất = Giá bất động sản - Giá nhà).

Bài báo đã thu thập được 315 giá đất ở các vị trí như trong Hình 3. Trong đó, 297 giá đất dùng để nội suy tính giá thị trường và 18 giá đất dùng để kiểm tra độ chính xác của các phép nội suy.

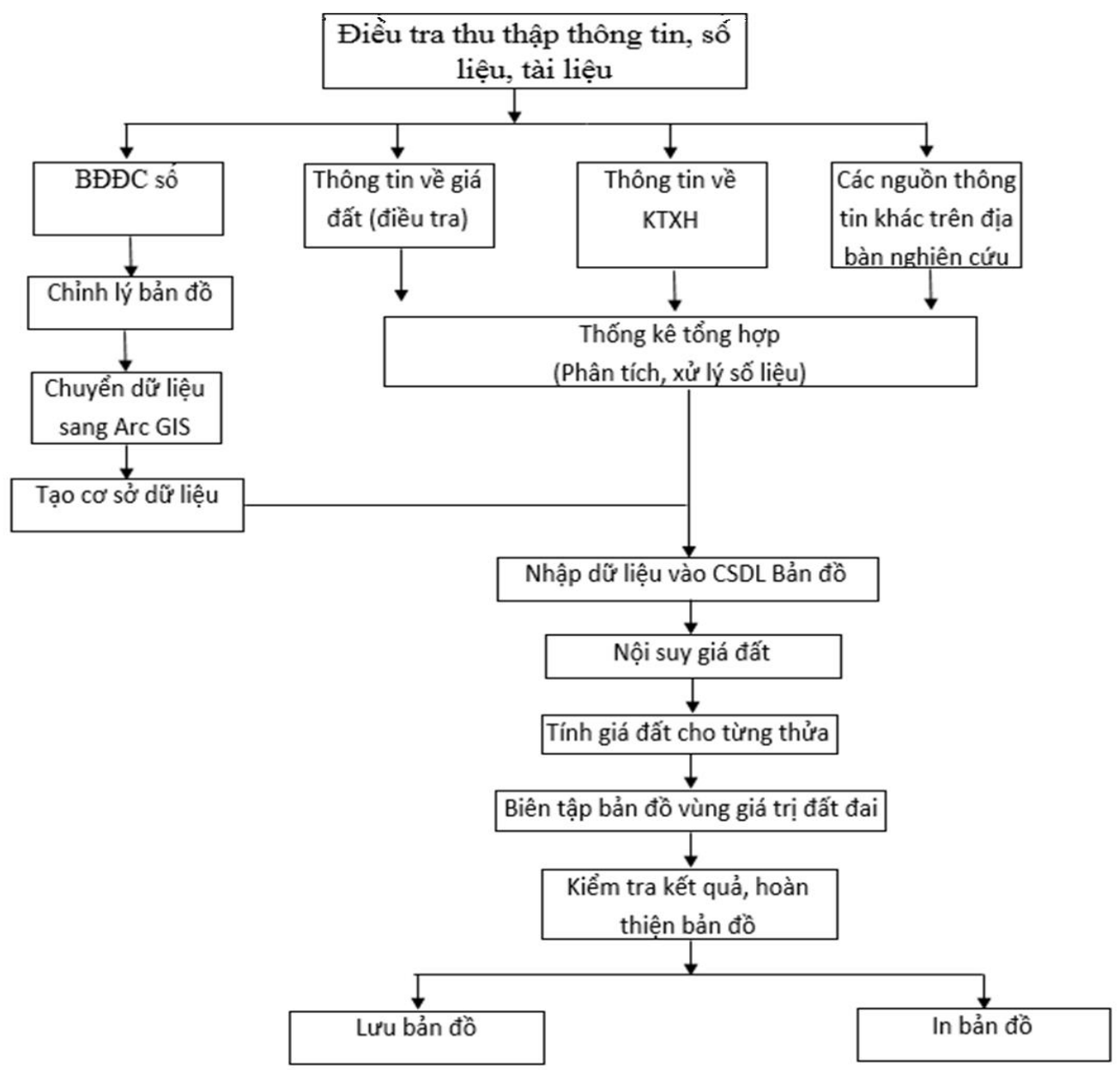

Hình 2. Quy trình thành lập bản đồ vùng giá trị đất đai theo giá trị thị trường. 


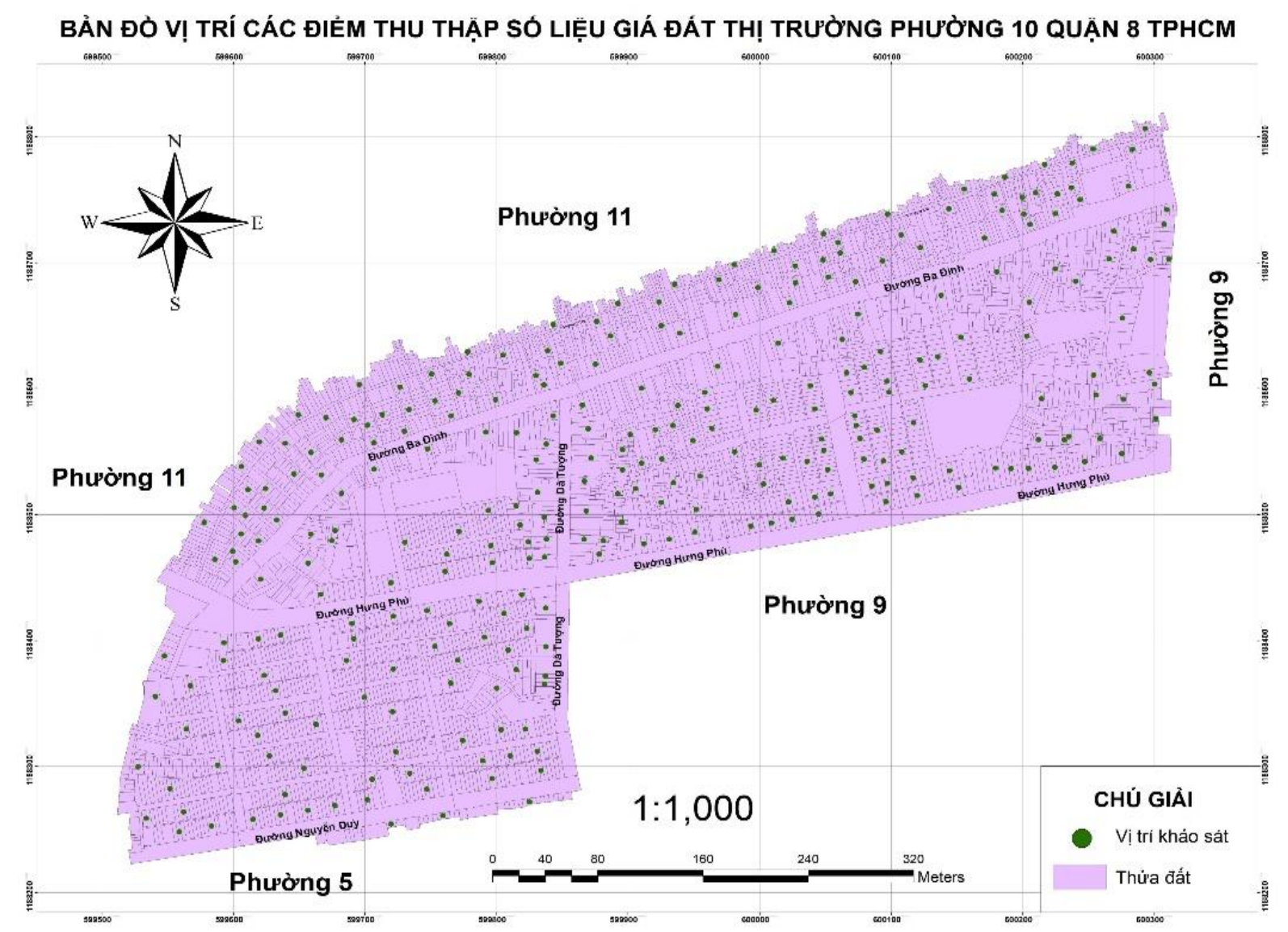

Hình 3. Bản đồ vị trí các điểm thu thập số liệu giá đất.

\subsection{Phân tích và xử lý số liệu}

Việc phân tích và xử lý số liệu (vị trí như Hình 3) được thực hiện với 2 nội dung chính là lọc dữ liệu và tính các hệ số ảnh hưởng đến giá đất thị trường. Hai nội dung đó được cụ thể như sau:

\subsubsection{Loc dũ liệu}

Để xây dựng được bản đồ giá đất đúng nhất, giá đất cập nhật mới nhất thì nhóm tác giả sử dụng phương pháp phân tích tương quan, phân tích sự phù hơp quy luật về giá của thửa đất so với các thửa đất xung quanh để loại bỏ đi những thửa đất không theo quy luật như nhỏ quá hay lớn quá so với giá điều tra. Đồng thời loại bỏ đi những thửa đất có tình trạng pháp lý chưa rõ ràng, vẫn còn đang trong tình trạng tranh chấp.

Để thuận tiện cho việc điều tra và xử lý số liệu, bài báo đã khoanh thành 3 vùng giá trị dựa theo khu vực và tuyến phố chính của phường.

Vùng 1: Khu vực xung quanh đường Nguyễn Duy, đường Dã Tượng;
Vùng 2: Khu vực xung quanh đường Ba Đình, đường Ụ cây;

Vùng 3: Khu vực xung quanh đường Hưng Phú, đường Phạm Hùng.

\subsubsection{Tính hệ số ảnh hưởng đến giá đất thị trường}

Trong quá trình phân tích cũng cần tính đến các hệ số ảnh hưởng đến giá đất như: hệ số vị trí, hệ số diện tích, hệ số hình thể.

Như vậy, để đánh giá được mức độ ảnh hưởng của từng yếu tố đến giá thị trường của thửa đất, bài báo áp dụng một trong những phương pháp thông dụng là chọn ra những cặp mẫu điều tra có các yếu tố tương tự nhau, trừ yếu tố phân tích để tìm ra hệ số ảnh hưởng của từng yếu tố đối với giá trị thị trường của thửa đất.

\section{a. Tính hệ số vị trí (K_VT)}

Thông qua việc phân tích số liệu giá đất thị trường nhóm tác giả đã xác định được 4 vị trí ảnh hưởng lớn đến thửa đất và hệ số tương ứng của chúng. Vị trí 1 thửa đất giáp với với đường có tên 
đường, Vị trí 2 thửa đất giáp với hẻm có độ rộng hơn $5 \mathrm{~m}$, hai xe ô tô có thể tránh nhau được. Vị trí 3 thửa đất giáp với hẻm có độ rộng $3 \div 5 \mathrm{~m}$, xe ô tô có thể vào được. Vị trí 4 áp dụng đối với các thửa đất còn lại. Vì vị trí 1 là vị trí mặt tiền thuận lợi giao thông và kinh doanh nên giá đất cao nhất và được chọn làm chuẩn có hệ số là 1 . Áp dụng phương pháp trọng số các yếu tố (Factor Rating Method) để tính toán hệ số của 3 nhóm còn lại và kết quả được thể hiện ở Bảng 1.

Bảng 1. Ảnh hưởng của hệ số vị trí.

\begin{tabular}{|c|c|c|c|c|}
\hline Vùng & Vị trí 1 & Vị trí 2 & Vị trí 3 & Vị trí 4 \\
\hline 1 & 1 & 0,7 & 0,56 & 0,448 \\
\hline 2 & 1 & 0,7 & 0,56 & 0,448 \\
\hline 3 & 1 & 0,7 & 0,56 & 0,448 \\
\hline
\end{tabular}

b. Tính hệ số diện tích (K_DT)

Hệ số diện tích được chia làm 3 nhóm cho từng vùng:

Nhóm 1: nhỏ hơn $36 \mathrm{~m}^{2}$;

Nhóm 2: trong khoảng 36 $\div 100 \mathrm{~m}^{2}$;

Nhóm 3: lớn hơn $100 \mathrm{~m}^{2}$.

Vì phường chủ yếu là đất ở dùng để xây nhà kết hợp với kinh doanh, ít dùng vào mục đích chính là sản xuất kinh doanh nên nhóm 2 có giá cao nhất và được chọn làm chuẩn có hệ số là 1 . Áp dụng phương pháp trọng số các yếu tố (Factor Rating Method) để tính toán hệ số của 2 nhóm còn lại và kết quả được thể hiện ở Bảng 2.

Bảng 2. Ảnh hưởng của hệ số diện tích.

\begin{tabular}{|c|c|c|c|}
\hline Vùng & Nhóm 1 & Nhóm 2 & Nhóm 3 \\
\hline 1 & 0,98 & 1 & 0,76 \\
\hline 2 & 0,95 & 1 & 0,88 \\
\hline 3 & 0,97 & 1 & 0,75 \\
\hline
\end{tabular}

c. Tính hệ số hình thể (K_HT)

Hình thể của thửa đất được chia làm 3 nhóm:

Nhóm 1: Hình vuông;

Nhóm 2: Hình chữ nhật;

Nhóm 3: Hình đa giác.

Trong đó, hình chữ nhật là nhóm hình thể được ưa chuộng nhất và gán hệ số là 1 . Áp dụng phương pháp trọng số các yếu tố sẽ tính được hệ số hình thể của 2 nhóm hình thể còn lại (Bảng 3 ).

Bảng 3. Bảng tổng hợp hệ số hình thể của tùng vùng giá trị.

\begin{tabular}{|c|c|c|c|}
\hline Vùng & Nhóm 1 & Nhóm 2 & Nhóm 3 \\
\hline 1 & 0,97 & 1 & 0,84 \\
\hline 2 & 0,94 & 1 & 0,79 \\
\hline 3 & 0,96 & 1 & 0,82 \\
\hline
\end{tabular}

\subsection{Nội suy giá đất}

Do lớp "giá thu thập" đang chứa một số yếu tố ảnh hưởng như vị trí, diện tích, hình thể,... Để nội suy, cần tạm thời loại bỏ các yếu tố đó để có được một lớp mới gọi là lớp giá quy chuẩn. Giá quy chuẩn được tính theo công thức (2).

$$
\begin{gathered}
\text { Gia_quy_chuan }=g i a_{-} t h u_{-} \text {thap } / K \_H T^{*} \\
K_{-} V T^{*} K_{-} D T
\end{gathered}
$$

Bài báo sử dụng 3 phương pháp nội suy:

Nội suy trọng số (IDW - Inverse Distance Weighted); Nội suy hàm Spline và Nội suy Kriging. Sau khi nội suy sẽ có được giá trị của từng Cell (giá quy chuẩn) trong khu vực nghiên cứu tương ứng với 3 phương pháp.

Để đánh giá độ tin cậy kết quả nội suy, bài báo đã sử dụng 18 mẫu giá còn lại để so sánh và đánh giá với kết quả được trình bày như Bảng 4.

Bảng 4. Bảng so sánh kết quả nội suy giá đất so với giá đất thực tế thu thập được (triệu đồng/m²).

\begin{tabular}{|c|c|c|c|c|c|c|c|c|}
\hline Số tờ / Số thưa & $1 / 11$ & $2 / 67$ & $7 / 119$ & $12 / 70$ & $14 / 121$ & $15 / 134$ & $21 / 90$ & $26 / 14$ \\
\hline Giá & 94 & 59 & 96 & 79 & 61 & 96,5 & 140 & 112 \\
\hline Giá thu thập & 93,636 & 58,919 & 95,89 & 79,417 & 60,655 & 96,709 & 139,475 & 111,856 \\
\hline Giá theo nội suy IDW & 0,364 & 0,081 & 0,110 & $-0,417$ & 0,345 & $-0,209$ & 0,525 & 0,144 \\
\hline Sai số & 94,882 & 60,306 & 95,873 & 80,072 & 61,389 & 96,823 & 139,42 & 111,523 \\
\hline Giá theo nội suy Spline & $-0,882$ & $-1,306$ & 0,127 & $-1,072$ & $-0,389$ & $-0,323$ & 0,576 & 0,477 \\
\hline Sai số & 93,722 & 58,585 & 96,782 & 80,023 & 60,764 & 97,24 & 139,8 & 110,985 \\
\hline Giá theo nội suy Kriging & 0,278 & 0,415 & $-0,782$ & $-1,023$ & 0,236 & $-0,74$ & 0,2 & 1,015 \\
\hline Sai số & \multicolumn{7}{|r|}{} \\
\hline
\end{tabular}


Từ kết quả trên, nhận thấy phép nội suy IDW là phù hợp nhất cho khu vực Phường 10, Quận 8. Do vậy, bái báo sẽ lựa chọn kết quả nội suy IDW để xây dựng cơ sở dữ liệu giá đất theo giá thị trường ở Phường 10, Quận 8. Quy trình nội suy để có giá đất thực được thể hiện ở Hình 4. Việc sử dụng phép nội suy sẽ thu được giá trị của từng ô (cell) trên bản đồ. Một thửa đất là tập hợp của nhiều ô. Sau đó, sử dụng công cư thống kê theo vùng (Zonal Statistics as Table) của ArcGIS sẽ cho ra giá trị trung bình của các thửa đất. Các giá trị này được liên kết với bảng thuộc tính của lớp "Thua_dat" qua trường liên kết là "ID". Sau khi thực hiện xong quá trình Zonal Statistics as Table, sẽ kết nối với bảng thuộc tính của lớp thửa đất để cho giá trị trung bình của từng thửa đất. Từ các giá trị trung bình này, giá thực của các thửa đất sẽ được tính khi nhân ngược trở lại với các hệ số ảnh hưởng theo công thức (3).

$$
\text { Gia_thuc }=\text { Gia trung binh } \times K_{V T} \times K_{H T} \times K_{D T} X
$$

Trong đó: $k$ - hệ số ảnh hưởng các yếu tố đến giá đất. Giá thực theo thị trường của Phường 10, Quận 8 được thể hiện trong Hình 5.

\subsection{So sánh giá thị trưòng và khung giá nhà nước}

Quy trình xác định hệ số chênh lệch giữa giá đất thị trường và giá đất nhà nước quy định được thể hiện trên Hình 6.

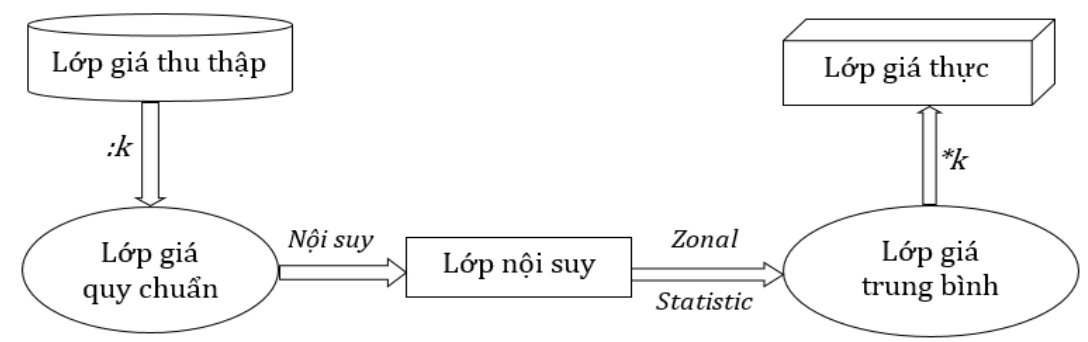

Hình 4. Quy trình nội suy giá đất (k là hệ số ảnh hưởng của các yếu tố đến giá đất).

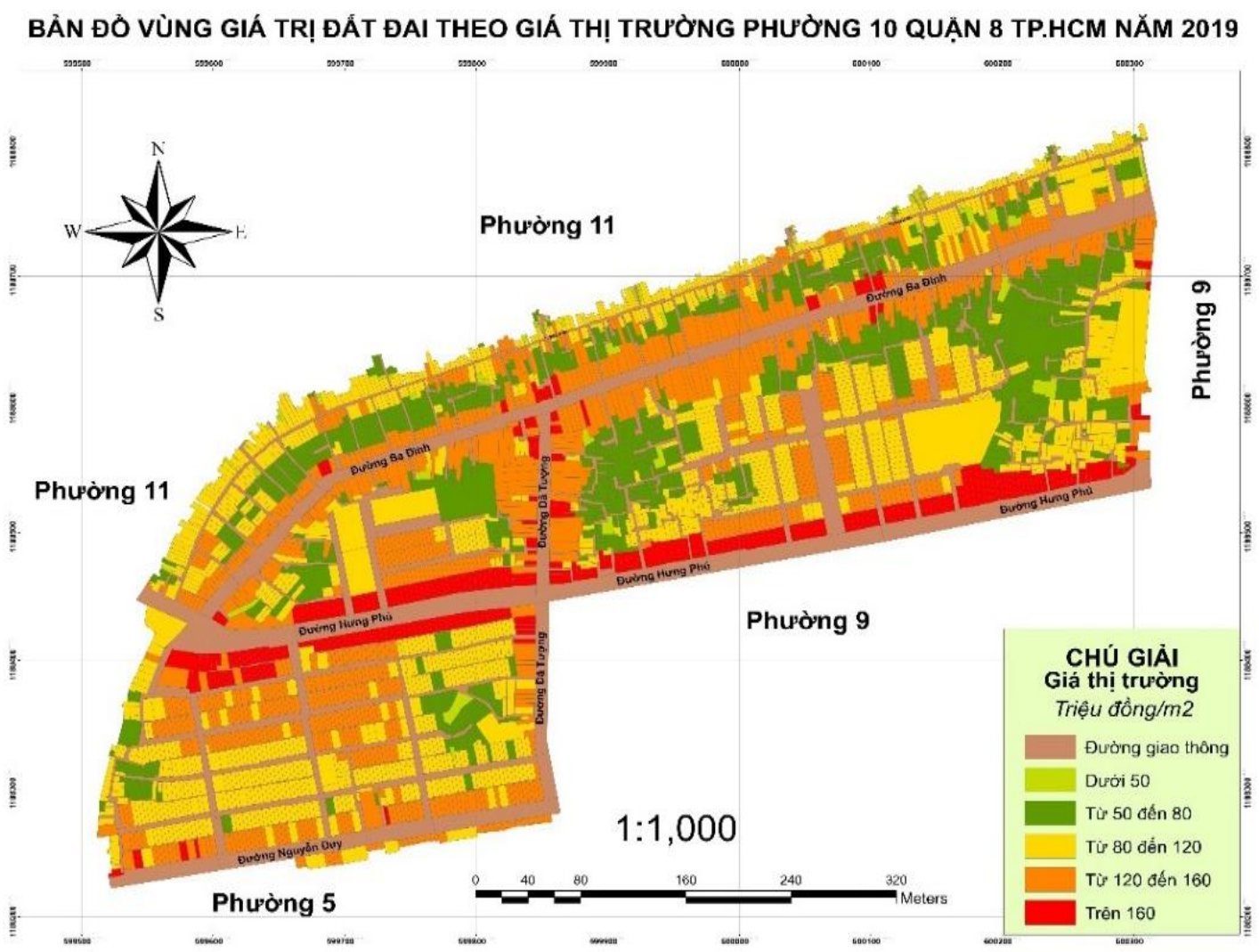

Hình 5. Bản đồ vùng giá trị đất theo giá thị trường. 
Để tính toán hệ số chênh lệch giữa giá đất thị trường và giá đất nhà nước quy định thì cần chồng xếp hai bản đồ vùng giá trị đất đai theo khung giá nhà nước và bản đồ vùng giá trị đất đai theo giá thị trường. Trường thông tin chênh lệch "HS_chenhlech" (lưu trữ sự chênh lệch giá đất giữa hai bản đồ) trong bảng thuộc tính được tính toán HS_chenhlech theo công thức (4).

\section{HS_chenhlech = Giá thị trường / Giá theo khung giá}

Bảng 5 là hệ số chênh lệch giá đất giữa giá nhà nước và giá thị trường. Hệ số chênh lệch thấp nhất là 15,6; cao nhất là 23 ; trung bình là 19,8.

\subsection{Thảo luận}

Trên cơ sở bảng hệ số chênh lệch thành lập được, có thể thấy rằng giá thị trường của các thửa đất đều cao hơn khoảng $20 \div 23$ lần với giá trong khung giá do UBND Thành phố ban hành.

- Khu vực xung quanh đường Ụ Cây có giá chênh lệch cao nhất. Các thửa đất của khu vực này chủ yếu ở vị trí 1,2 ; đây là tuyến đường hiện đang phát triển giao thông tấp nập của phường.

- Giá chênh lệch thấp thường nằm tại khu vực các vị trí 3,4 . Hầu hết thường ở trong ngõ với điều kiện giao thông kém.

\section{Kết luận}

Đất đai vừa là sản phẩm của tự nhiên vừa là sản phẩm của lao động tham gia vào thị trường như một hàng hoá đặc biệt, ảnh hưởng trực tiếp đến nền kinh tế và đặc biệt thị trường $B Đ S$ trong những năm gần đây pfhát triển một cách nhanh chóng, không những ảnh hưởng đến nền kinh tế mà còn ảnh hưởng trực tiếp đến đời sống của người dân. Vì vậy, bản đồ vùng giá trị đất đai là một công cụ quan trọng cùng với cơ sở pháp lý và tổ chức phục vụ cho công tác quản lý đất đai và phát triển thị trường bất động sản công khai và minh bạch hơn. Đồng thời, đây cũng là phương tiện tra cứu nhanh chóng, trực quan cho người dân. Trước đây, khi công nghệ chưa phát triển thì việc xây dựng bản đồ vùng giá trị đất đai và tra cứu thông tin gặp rất nhiều khó khăn vì phải xử lý một khối lượng thông tin lớn liên quan đến giá đất, nhưng ngày nay công việc này trở nên dễ dàng hơn khi ứng dụng công nghệ GIS, vì một số bước sẽ được tự động hoá bằng chức năng của GIS.

Kết quả nghiên cứu cho thấy khả năng ứng dụng hiệu quả công nghệ GIS vào xây dựng bản đồ vùng giá trị đất đai, đã nghiên cứu xây dựng được bản đồ vùng giá trị đất đai theo khung giá nhà nước và theo giá thị trường ở Phường 10 , Quận 8 , TP.HCM, bản đồ thể hiện sự chênh lệch giữa khung giá nhà nước và giá thị trường năm 2019.

\section{Kiến nghị}

- Nhà nước và các cán bộ quản lý đất đai cần có sự điều chỉnh giá đất hợp lý cho khu vực Phường 10, Quận 8 để đảm bảo công bằng cho người dân và hạn chế các vụ tranh chấp đất đai.

Bảng 5. Hệ số chênh lệch giũa khung giá nhà nước và giá thị trường.

\begin{tabular}{|c|c|c|c|c|c|c|c|c|c|c|}
\hline TT & $\begin{array}{c}\text { Số tờ } \\
\text { bản } \\
\text { đồ }\end{array}$ & \begin{tabular}{|c} 
Số \\
hiệu \\
thửa
\end{tabular} & $\begin{array}{l}\text { Diên } \\
\text { tích } \\
\left(\mathrm{m}^{2}\right)\end{array}$ & Tên chủ sử dụng & Địa chỉ & $\begin{array}{l}\mathrm{M} \\
\mathrm{SD}\end{array}$ & $\begin{array}{c}\text { Giá nhà } \\
\text { nước }\end{array}$ & $\begin{array}{l}\text { Giá thị } \\
\text { trường }\end{array}$ & $\begin{array}{l}\text { Hệ số } \\
\text { chênh } \\
\text { lệch }\end{array}$ & \begin{tabular}{|c}
$\%$ \\
chênh \\
lệch \\
\end{tabular} \\
\hline 1 & 1 & 1 & 48,6 & Nguyễn Thành Danh & 45 Ụ Cây & ODT & 4.800 .000 & 88.046 .668 & 18,34 & 5,45 \\
\hline 2 & 1 & 3 & 17,7 & Trần Thị Muồi & 52 Ụ Cây & ODT & 4.800 .000 & 87.357 .079 & 18,2 & 5,49 \\
\hline 3 & 1 & 4 & 24 & Nguyễn Văn Sơn & 52A Ụ Cây & ODT & 4.800 .000 & 86.191 .521 & 17,96 & 5,57 \\
\hline 4 & 1 & 2 & 28,5 & Nguyễn Văn Thành & 50A Ụ Cây & ODT & 4.800 .000 & 74.797.874 & 15,58 & 6,42 \\
\hline 5 & 1 & 5 & 27,1 & Nguyễn Thị Thu & 54 Ụ Cây & ODT & 4.800 .000 & 89.887.131 & 18,73 & 5,34 \\
\hline 6 & 1 & 7 & 44,9 & Huỳnh Thị Liên & 52B Ụ Cây & ODT & 4.800 .000 & 93.652 .832 & 19,51 & 5,13 \\
\hline \multicolumn{11}{|l|}{$\ldots$} \\
\hline & & & & & & & & & & \\
\hline 3703 & 27 & 57 & 19,2 & CTXD Tân Bình Đông & Nguyễn Duy & ODT & 8.400 .000 & 127.882 .149 & 15,22 & 6,57 \\
\hline 3704 & 27 & 50 & 50,6 & Thái Thịnh Thi & 436 Nguyễn Duy & ODT & 8.400 .000 & 126.346 .130 & 15,04 & 6,65 \\
\hline 3705 & 27 & 2 & 36,8 & Quách Phương & Nguyễn Duy & ODT & 5.880 .000 & 86.310 .547 & 14,68 & 6,81 \\
\hline 3706 & 27 & 55 & 18,6 & CTXD Tân Bình Đông & Nguyễn Duy & ODT & 8.400 .000 & 127.101.845 & 15,13 & 6,61 \\
\hline 3707 & 27 & 52 & 50,4 & Lâm Kiên & 432 Nguyễn Duy & ODT & 8.400 .000 & 126.387 .482 & 15,05 & 6,65 \\
\hline 3708 & 27 & 53 & 40 & CTXD Tân Bình Đông & Nguyễn Duy & ODT & 8.400 .000 & 125.282 .974 & 14,91 & 6,70 \\
\hline
\end{tabular}


- Chú trọng đào tạo đội ngũ cán bộ mang tính toàn diện hơn, sâu hơn cả về chuyên môn lẫn công nghệ thông tin.

- Nhà nước cần phải xây dựng bản đồ vùng giá trị đất đai cho mỗi tỉnh thành một cách đồng bộ thống nhất bằng những cơ quan chuyên trách. Đây sẽ là nguồn tài nguyên chung để phục vụ quản lý đất đai và phát triển thị trường bất động sản.

- Để người dân dễ dàng tiếp cận và tra cứu thì cơ quan chức năng cần tăng cường giải pháp đưa thông tin lên mạng internet.

Ngoài ra, bài báo còn cung cấp thông tin khách quan về giá đất thực tế cho các nhà quản lý, giúp các nhà quản lý xây dựng các biện pháp phù hợp trong việc phân bổ, đền bù đất bị thu hồi và quản lý thị trường bất động sản một cách hiệu quả nhất. Bên cạnh đó, phương pháp nghiên cứu của bài báo nếu được áp dụng rộng rãi cho toàn thành phố cũng sẽ đưa ra thông tin về giá đất đáng tin cậy nhất, phục vụ hiệu quả cho người dân tham gia thị trường bất động sản.

\section{Đóng góp của các tác giả}

Hoàng Hữu Đức, Phạm Thị Làn: lên ý tưởng; Lê Thị Thu Hà, Nguyễn Hoàng Phi, Dương Quốc Hải, Lưu Hoàng Huynh: thu thập dữ liệu; Hoàng Hữu Đức, Nguyễn Thành Hiếu, Khuất Duy Cường: xử lý dữ liệu; Hoàng Hũu Đức, Phạm Thị Làn: viết bản thảo báo cáo, đánh giá và chỉnh sửa.

\section{Tài liệu tham khảo}

Atansah Sembiring, Nazaruddin Matondang, Sugiharto Pujangkoro. (2019). Analysis of Factors Affecting Housing Property Values Simple Type at Davarel Green Village Housing. IOSR Journal of Business and Management (IOSR - JBM) e - ISSN: 2278 487X, p - ISSN: 2319 - 7668, 21(5). Ser. IX (May. 2019), 88 - 92.

Hermawan, A., \& Syahbana, J. (2015). Pemetaan Perkembangan Perhotelan Di Pusat Perdagangan Dan Jasa Kota Semarang Dengan Sistem Informasi Geografis. Geoplanning: Journal of Geomatics and Planning, 2(1), 38 - 50. [CrossRef].
Trịnh Lữu Lien. (2014). Kỹ thuật xây dựng vùng giá đất, vùng giá trị đất đai phục vụ định giá đất, trên cơ sở dữ liệu địa chính, công nghệ GIS và ảnh viẽn tham. Tạp chí Khoa học \& Công nghê, 120(06), 127 - 132.

Paul B. Downing, (1973). Factors Affecting Commercial Land Values: An Empirical Study of Milwaukee, Wisconsin. Land Economics, 49(1), 44 - 56.

Aliyu Ahmad Aliyu, Abdu Ibrahim Garkuwa, Ibrahim Suma Singhry and Haruna Adamu. (2016). Impacr of school accessiblity on residential property values: evidence from existing frontier of knowlodge. The acadamic conference of berkeley research and publications international on exploring subsahara Afican Resources of Sustainable Development in the Milennium, 3(4).

Ryan Rivas, Dinesh Patil, Vagelis Hristidis, Joseph R.Barr and Narayanan Srinivasan. (2019). The impact of colleges and hospitals to local real estate markets. Journal of Big Data. 6(7), 1-24.

Waddell P, Berry BJ, Hoch I. (1993). Residential property values in a multinodal urban area: new evidence on the implicit price of location. J. Real Estate Finan Econ, 7(2),117-41.

Turner, J. (2017). The impact of walkability on home values: fndings from neighborhoods in three Bay Area cities. Digital Commons @ Cal Poly. 2017. http://digitalcommons.calpoly.edu /cgi/viewcontent.cgi?article $=1178 \&$ context $=c$ rpsp. Accessed Sept 2017.

Oni Ayotunde Olawande, Oluwatayo Adedapo and DurodolaDaniel O. (2012). European Scientific Journal December edition, 8(28). ISSN: 1857 - 7881 (Print) e - ISSN 1857- 7431

Van Praag B., Baarsma B. E. (2001). The shadow price of aircraft noise nuisance. Tinbergen Institute Discussion Paper, No. 01-010/3.

Ozdenerol E., Huang Y., Javadnejad F., Antipova A. (2015). The impact of trafc noise on housing values.J Real Estate Pract Educ.,18(1),35-54 